\title{
Recovery in hydrocephalic dementia after shunt operation
}

\author{
LARS G USTAFSON A N D O H A G B R G \\ From the Departments of Psychiatry I and Clinical Psychology, University Hospital, Lund, Sweden
}

SUMMARY Twenty-three patients with hydrocephalic dementia were studied before and after shunt operation, and improvement was found in 12. Before operation, the improved cases showed more symptoms of confabulation, gait disturbance, urinary incontinence, lack of insight, and constructional apraxia. The improvement was also most marked in these symptoms. The significance of general versus specific symptoms, duration, and aetiology is discussed from a differential diagnostic standpoint, and we conclude that the adequate and early diagnosis of hydrocephalic dementia is essential for good outcome after shunt operation, and that psychiatric and psychometric evaluation enable such a diagnosis to be made.

A syndrome of progressive mental deterioration and neurological disturbances, such as unsteady gait and urinary incontinence, has been described as characteristic of so-called normal pressure hydrocephalus (Adams et al., 1965). Patients with this syndrome showed memory failure, disorientation, and psychomotor retardation. In the further work on delineation of the syndrome, also called low pressure hydrocephalus, adult occult hydrocephalus or, with a more neutral term, hydrocephalic dementia (Granville-Grossman, 1971), symptoms such as apathy, emotional indifference, lack of insight (Braham et al., 1969; Messert and Wannamaker, 1974; Patzold et al., 1974), hostility, and aggressiveness (Crowell et al., 1973) have been emphasised. Theander and Granholm (1967) characterised the amnestic dysfunction in patients with hydrocephalus after subarachnoid haemorrhage as resembling that of Korsakoff's psychosis.

Clinical improvement has been reported after ventriculoatrial shunt operation in about $50 \%$ of patients with normal pressure hydrocephalus (Salmon, 1969; Salmon et al., 1971; Messert and Wannamaker, 1974). The possibility of a successful cure emphasises the importance of an adequate recognition of the syndrome. The diagnosis has been based almost exclusively on clinical evalua-

Supported by the Swedish Medical Research Council project 25X03950.

Address for reprint requests: Dr Lars Gustafson, Psychiatric Clinic, Lund University, Lasarettet, S-221 85 Lund, Sweden.

Accepted 30 May 1978 tion including neuroradiology and measurement of cerebrospinal fluid (CSF) physiology. Reports on systematic psychometric evaluation for differential diagnosis and for follow-up after shunt $\varnothing$ operation are scarce (McHugh and Goodell, 1966; Salmon et al., 1971; Collignon et al., 1975). Granholm and Svendgaard (1972) found that acute onset and a clinical picture dominated by dysmnesia predicted good outcome after shunt operation. The definite diagnosis of normal pressure hydrocephalus is still an important clinical problem even when diagnostic procedures such as RISA cisternography and computerised axial tomography scan are available. Problems of differential diagnosis are frequently encountered, especially against other organic dementias, such as Alzheimer's disease and multi-infarct dementia (Coblentz et al., 1973; Earnest et al., 1974; Katzman, 1976). The present report focuses upon psychiatric and psychometric findings in demented patients in whom clinical, neuroradiological, and CSF findings indicated hydrocephalus. Our aim was to examine whether there are specific psychometric dysfunctions and psychiatric disturbances within the symptom pattern of hydrocephalic dementia. If so, are patients with a preponderance of such characteristics more liable to improve after shunt operation?

\section{Patients and methods}

Twenty-three patients (14 men and nine women) with hydrocephalic dementia, who later underwent 
ventriculoatrial shunting, were selected from patients referred to the Psychiatric Clinic for psychiatric and psychometric evaluation. The diagnosis of hydrocephalic dementia was based on clinical investigations, including pneumoencephalography and RISA cisternography, performed at the Departments of Neurology, Neurosurgery, and Neuroradiology, University Hospital of Lund. The shunt operations were carried out at the Department of Neurosurgery. The mean age of the patients was $57.3 \pm 10.1$ years (range 36-70 years), and the mean duration of the disease, which could be estimated in 21 patients, was $2.9 \pm 2.7$ years (range $0.25-10$ years).

A positive or tentative cause of the hydrocephalus was established before the shunt operation in all but five cases. There were five cases with a history of subarachnoid haemorrhage, seven cases with skull trauma, two cases with aqueduct obstruction, and one case with an Arnold-Chiari malformation. Two cases had previously been operated on for pituitary adenoma and ependymoma respectively, and one case had had a meningoencephalitis. Three cases with head injuries had also abused alcohol. In two cases with idiopathic hydrocephalic dementia, necropsy several years after the shunt operation revealed multiple cerebral infarcts. In one case with a history of skull trauma, the postmortem neuropathological investigation showed changes compatible with Alzheimer's disease.

As reference groups, we used one group of agematched control subjects (Hagberg and Ingvar, 1976) and three groups of patients with presenile dementia-groups C 2 and C 3, and patients with Alzheimer's disease. Group C 2 with a selective memory disturbance and group $C 3$ with a general cognitive reduction have been presented fully elsewhere (Gustafson and Hagberg, 1975; Hagberg and Ingvar, 1976). The group with Alzheimer's disease contained 17 consecutive cases with this diagnosis, their mean age was $59.6 \pm 4.5$ years, and the duration of the disease was $4.7 \pm 2.0$ years.

Psychiatric rating and psychometric testing were carried out a few days before the ventriculoatrial shunt operation, and seven to 10 days after and three to six months after the operation.

\section{PSYCHIATRIC EVALUATION}

This was done by one of us (LG) using a formalised rating scale for psychiatric symptoms (Gustafson and Risberg, 1974; Gustafson, 1975; Gustafson and Hagberg, 1975). The symptom ratings have, in other studies of patients with presenile dementia, been validated against regional cerebral blood flow, and with neuropathological findings in deceased patients (Gustafson et al., 1972; Gustafson and Risberg, 1974; Brun and Gustafson, 1976; Gustafson et al., 1977). The patient's behaviour was also rated by the nursing staff and by members of the family using two formalised rating scales. The items of these latter scales were partly identical with that used by the psychiatrist but also included information on the patient's practical abilities.

PSYCHOMETRIC TESTS

Seven psychometric methods measuring intellectual functions most liable for deterioration in organic dementia were used. Paired associates measures immediate recall of verbal material (Cronholm and Molander, 1954). Two parallel versions were used. Memory for design assesses the spatial perceptive ability and the immediate memory for simple geometric designs. The score analysis is presented in terms of error points (Graham and Kendall, 1960). Visual retention test is considered to test conceptual memory (Benton, 1963). It uses more figures per trial than memory for design, but the figures are simpler. Three parallel versions were used. Vocabulary was tested using conventional word definition test (Husen, 1956). Block design aims to measure spatial performance as well as inductive capacity. The present version is based on the block design in the Wechsler Bellevue Intelligence Score (Wechsler, 1958). Colour word test, a version of the Stroop Color word test was used here to assess cognitive flexibility and intellectual speed. The time for reading the printing-colour which is incongruent with the word is measured (Smith and Nyman, 1959). Reaction time test, simple and choice, measures speed of a motor response to visual stimuli (light) either single or as a choice between three lights.

All tests were given before operation. The visual retention, colour word, and reaction time tests were given again immediately after operation, and all tests except memory for design and vocabulary were repeated at follow-up.

The degree of cognitive reduction relative to the estimated premorbid level is rated on a four point scale: (1) mild reduction $=$ preserved verbal ability and dysfunction in a single test not exceeding 2 stanine; (2) moderate reduction $=$ preserved verbal ability and dysfunction in a single test exceeding 2 stanine; (3) marked reduction $=$ dysfunction in all tests exceeding 2 stanine; (4) severe cognitive reduction $=$ verbal reduction with anomia or aphasia. The patients cannot copy memory for design and/or visual retention test patterns. 


\section{Results}

Considerable clinical homogeneity was found in the 23 cases. The preoperative clinical picture was dominated by loss of vitality, weariness, emotional deterioration, memory failure, confabulation, disorientation, gait disturbance, and urinary incontinence. The patients showed a remarkable lack of insight, sometimes best described as neglect, about their alarming symptoms. The slow, tired, and disinterested appearance of the patients could suddenly change to irritability and

Table 1 Psychiatric symptoms in hydrocephalic dementia before and after shunt operation, and in Alzheimer's disease. The number of patients with strong/slight evidence of the symptom is expressed as a quotient

\begin{tabular}{lccc}
\hline Psychiatric symptoms & $\begin{array}{l}\text { Hydrocephalic } \\
\text { dementia } \\
(n=23)\end{array}$ & & $\begin{array}{l}\text { Alzheimer's } \\
\text { disease } \\
(n=17)\end{array}$ \\
\hline Preoperative & Postoperative & \\
\hline Euphoria & $4 / 3$ & $3 / 3$ & $2 / 2$ \\
Inertia & $14 / 9$ & $6 / 14$ & $7 / 8$ \\
Emotional unconcern & $10 / 7$ & $4 / 8$ & $14 / 3$ \\
Anxiousness, depression & $2 / 3$ & $0 / 3$ & $6 / 5$ \\
Restlessness & $1 / 6$ & $2 / 6$ & $3 / 6$ \\
Disorientation & $10 / 6$ & $3 / 6$ & $9 / 8$ \\
Amnesia for recent & $15 / 6$ & & $17 / 0$ \\
events & $4 / 6$ & $14 / 3$ \\
Amnesia for remote & $4 / 10$ & $2 / 8$ & $0 / 4$ \\
events & $8 / 9$ & $3 / 5$ & $0 / 0$ \\
Confabulation & $3 / 0$ & $0 / 1$ & $9 / 6$ \\
Fantastic confabulation & $2 / 5$ & $3 / 3$ & $1 / 3$ \\
Apraxia & $12 / 6$ & $2 / 11$ & $2 / 1$ \\
Gait disturbance & $8 / 5$ & $4 / 4$ & $4 / 3$ \\
Urinary incontinence & $3 / 3$ & $3 / 2$ & $13 / 2$ \\
Dysarthria & $3 / 6$ & $4 / 4$ & \\
Expressive aphasia & & & \\
\hline
\end{tabular}

dysphoria when they were provoked by questions or other demands. The clinical findings before and after shunt operation are presented in Table 1 together with results from previously studied patients with Alzheimer's disease.

Before operation the patients with hydrocephalic dementia showed inertia, emotional unconcern, disorientation, and amnesia for recent events, which are similar to the symptoms in the cases of Alzheimer's disease. Confabulation, gait disturbance, and urinary incontinence were more frequently observed in the group with hydrocephalic dementia while amnesia for remote events apraxia, expressive aphasia, anxiousness, and restlessness were more common in the Alzheimer's disease group. Clinical improvement was found in 13 cases, while 10 patients appeared unchanged or somewhat deteriorated after the shunt operation. Table 2 shows the patient's preoperative test performance as test results from the four reference groups.

All patient groups deviated significantly from the control group. Moreover, there were significant differences between the performance of the patients with hydrocephalic dementia and those with presenile dementia. The patients with hydrocephalic dementia showed neither the focal memory dysfunction of group C 2, nor the general cognitive dysfunction observed in group $\mathrm{C} 3$. The 8 hydrocephalic patients showed a marked dys-0 function of inductive spatial ability with a lower performance in block design. This dysfunction is also obvious in spatioperceptual ability and spatial memory (memory for design plus visual retention

Table 2 Test performance in hydrocephalic dementia before operation, in patients with Alzheimer's disease, in patients with moderate degree of presenile dementia (C 2 and C 3, Hagberg and Ingvar, 1976), and in an age-matched control group

\begin{tabular}{|c|c|c|c|c|c|c|}
\hline \multirow[t]{2}{*}{ Test } & \multicolumn{2}{|r|}{$\begin{array}{l}\text { Control } \\
\text { group }\end{array}$} & $C 2$ & $C 3$ & $\begin{array}{l}\text { Hydrocephalic } \\
\text { dementia }\end{array}$ & $\begin{array}{l}\text { Alzheimer's } \\
\text { disease }\end{array}$ \\
\hline & $\begin{array}{l}\text { Number: } \\
\text { Mean age }(y r) \text { : }\end{array}$ & $\begin{array}{l}56 \\
55\end{array}$ & $\begin{array}{l}14 \\
55\end{array}$ & $\begin{array}{l}16 \\
56\end{array}$ & $\begin{array}{l}23 \\
57\end{array}$ & $\begin{array}{l}17 \\
60\end{array}$ \\
\hline Vocabulary & $\begin{array}{l}\text { Mean } \\
\text { SD }\end{array}$ & $\begin{array}{l}27.4 \\
10.9\end{array}$ & $\begin{array}{l}32.0 \\
11.2\end{array}$ & $\begin{array}{l}26.0 \\
13.7\end{array}$ & $\begin{array}{l}25.7 \\
13.9\end{array}$ & $\begin{array}{l}6.0 \\
7.8\end{array}$ \\
\hline $\begin{array}{l}\text { Paired associates } \\
\text { Memory for design }\end{array}$ & $\begin{array}{l}\text { Mean } \\
\text { SD } \\
\text { Mean } \\
\text { SD }\end{array}$ & $\begin{array}{r}16.5 \\
4.6 \\
2.8 \\
2.6\end{array}$ & $\begin{array}{r}11.2 \\
5.3 \\
7.2 \\
6.2\end{array}$ & $\begin{array}{r}11.7 \\
5.9 \\
10.1 \\
6.4\end{array}$ & $\begin{array}{l}8.8 \\
7.1 \\
8.5 \\
7.5\end{array}$ & $\begin{array}{r}0.2 \\
0.8 \\
24.0 \\
26.9\end{array}$ \\
\hline \multicolumn{7}{|l|}{ Visual retention } \\
\hline $\begin{array}{l}\text { Right } \\
\text { Wrong }\end{array}$ & $\begin{array}{l}\text { Mean } \\
\text { SD } \\
\text { Mean } \\
\text { SD }\end{array}$ & $\begin{array}{l}6.2 \\
1.6 \\
6.4 \\
3.2\end{array}$ & $\begin{array}{l}5.3 \\
2.2 \\
7.9 \\
4.5\end{array}$ & $\begin{array}{r}3.0 \\
1.5 \\
12.0 \\
3.7\end{array}$ & $\begin{array}{r}3.2 \\
1.6 \\
12.2 \\
4.5\end{array}$ & $\begin{array}{c}-0.2(n=2) \\
0.9 \\
18.3(n=4) \\
4.0\end{array}$ \\
\hline \multicolumn{7}{|c|}{$\begin{array}{l}\text { Memory for design and visual retention } \\
\text { (number of patients) }\end{array}$} \\
\hline $\begin{array}{l}\text { Can copy } \\
\text { Cannot copy }\end{array}$ & & $\begin{array}{l}\mathbf{0} \\
\mathbf{0}\end{array}$ & $\begin{array}{l}0 \\
0\end{array}$ & $\begin{array}{l}1 \\
0\end{array}$ & $\begin{array}{l}6 \\
3\end{array}$ & $\begin{array}{r}9 \\
19\end{array}$ \\
\hline Block design & $\begin{array}{l}\text { Mean } \\
\text { SD }\end{array}$ & $\begin{array}{r}21.0 \\
6.8\end{array}$ & $\begin{array}{r}19.9 \\
5.8\end{array}$ & $\begin{array}{l}9.5 \\
4.9\end{array}$ & $\begin{array}{l}5.7 \\
7.1\end{array}$ & $\begin{array}{l}0.8 \\
2.3\end{array}$ \\
\hline
\end{tabular}


tests) where $22 \%$ of the hydrocephalic dementia patients could not reproduce and $13 \%$ were unable to copy simple geometrical figures. The patients with Alzheimer's disease of approximately the same age performed extremely poorly on all tests including the verbal one, and did not show the test profiles of the other three patient groups.

Nine $(39 \%)$ ) of the 23 patients with hydrocephalic dementia showed an improved cognitive level after shunt operation, seven $(30 \%)$ patients appeared unchanged, and seven $(30 \%)$ patients showed a further cognitive reduction postoperatively. A comparison between psychometric and psychiatric evaluation of the postoperative outcome is shown in Table 3. There was good agreement between the two independent evaluations, and disagreement in only three cases. Two of these cases were found to be more alert in the test situation even if their performance did not improve, and were then grouped with the improved patients. This gave a twofold classification with 12 improved and 11 unimproved cases. These two outcome groups were compared with regard to background variables, psychiatric symptoms, and psychometric performance before treatment.

Table 3 Outcome of operation in hydrocephalic dementia as measured by psychometric tests and psychiatric evaluation

\begin{tabular}{|c|c|c|c|}
\hline & & $\begin{array}{l}\text { Psychomet } \\
\text { Improved }\end{array}$ & $\begin{array}{l}\text { valuation } \\
\text { Unimproved }\end{array}$ \\
\hline $\begin{array}{l}\text { Psychiatric } \\
\text { evaluation }\end{array}$ & $\begin{array}{l}\text { Improved } \\
\text { Unimproved }\end{array}$ & $\begin{array}{r}10 \\
0\end{array}$ & $\begin{array}{r}3 \\
10\end{array}$ \\
\hline
\end{tabular}

No significant difference was found as to mean age at the investigation or as to the preoperative degree of reduced cognition. However, the duration of the disease was significantly shorter in patients who improved (mean $=18.5$ months) compared to unimproved patients (mean $=57.0$ months) $(\mathrm{P}<0.005$, one-tailed $t$ test; McNemar, 1959).

Table 4 shows the distribution of psychiatric symptoms in the two outcome groups before and after shunt operation. Confabulation, gait disturbance, urinary incontinence, and emotional unconcern were more prominent before operation in patients who improved. On the other hand apraxia, expressive aphasia, and dysarthria were somewhat more frequent in the unimproved cases. Thus, the unimproved cases were more similar to the Alzheimer's disease group than the improved cases. Most patients with hydrocephalic dementia were capable of writing their own names. Only two patients, both belonging to the unimproved group, showed dysgraphia. The manifestation of symp-
Table 4 Psychiatric symptoms before and after shunt operation of hydrocephalic dementia in improved and unimproved cases. The number of patients with strong/slight evidence of the symptom is expressed as a quotient

\begin{tabular}{|c|c|c|c|c|}
\hline \multirow[t]{2}{*}{ Psychiatric symptom } & \multicolumn{2}{|c|}{$\begin{array}{l}\text { Improved cases } \\
(n=12)\end{array}$} & \multicolumn{2}{|c|}{$\begin{array}{l}\text { Unimproved cases } \\
(n=I I)\end{array}$} \\
\hline & $\begin{array}{l}\text { Before } \\
\text { operation }\end{array}$ & $\begin{array}{l}\text { After } \\
\text { operation }\end{array}$ & $\begin{array}{l}\text { Before } \\
\text { operation }\end{array}$ & $\begin{array}{l}\text { After } \\
\text { operation }\end{array}$ \\
\hline Euphoria & $3 / 1$ & $2 / 1$ & $1 / 2$ & $1 / 2$ \\
\hline Inertia & $9 / 3 \ddagger$ & $1 / 8$ & $5 / 6$ & $5 / 6$ \\
\hline Emotional unconcern & $7 / 2 \dagger$ & $1 / 3$ & $3 / 5$ & $3 / 5$ \\
\hline $\begin{array}{l}\text { Anxiousness, } \\
\text { depression }\end{array}$ & & & & \\
\hline $\begin{array}{l}\text { depression } \\
\text { Restlessness }\end{array}$ & $2 / 2$ & $0 / 2$ & $0 / 1$ & $0 / 1$ \\
\hline $\begin{array}{l}\text { Restlessness } \\
\text { Disorientation }\end{array}$ & $\begin{array}{l}0 / 4 \\
6 / 3^{*}\end{array}$ & $\begin{array}{l}0 / 4 \\
0 / 2\end{array}$ & $\begin{array}{l}1 / 2 \\
4 / 3\end{array}$ & $\begin{array}{l}2 / 2 \\
3 / 4\end{array}$ \\
\hline Amnesia for recent & & & & \\
\hline $\begin{array}{l}\text { events } \\
\text { Amnesia for remote }\end{array}$ & $8 / 3 *$ & $1 / 2$ & $7 / 3$ & $5 / 4$ \\
\hline events & $2 / 6$ & $0 / 3$ & $2 / 4$ & $2 / 5$ \\
\hline $\begin{array}{l}\text { Confabulation } \\
\text { Fantastic }\end{array}$ & $6 / 3^{*}$ & $0 / 2$ & $2 / 6$ & $3 / 3$ \\
\hline confabulations & $2 / 0$ & $0 / 0$ & $1 / 0$ & $0 / 1$ \\
\hline Apraxia & $0 / 2$ & $0 / 1$ & $2 / 3$ & $3 / 2$ \\
\hline Gait disturbance & $8 / 3 \ddagger$ & $0 / 7$ & $4 / 3$ & $2 / 4$ \\
\hline Urinary incontinence & $5 / 4^{\circ}$ & $1 / 3$ & $3 / 1$ & $3 / 1$ \\
\hline Dysarthria & $0 / 1$ & $0 / 0$ & $3 / 2$ & $3 / 2$ \\
\hline Expressive aphasia & $0 / 3$ & $0 / 2$ & $3 / 3$ & $4 / 2$ \\
\hline
\end{tabular}

Significance levels (Fisher's exact probability test) indicate difference between preoperative and postoperative ratings as follows: $\mathrm{P}<0.025^{*}$, $\mathbf{P}<0.01 \dagger, \mathrm{P}<0.005 \ddagger$

toms before and after operation was compared within the outcome groups. Inertia, emotional unconcern, disorientation, amnesia for recent events, confabulation, and gait disturbance were significantly reduced in the improved cases after operation. The decrease of urinary incontinence was almost significant (Fisher's exact probability test). No significant symptom changes were found in the unimproved group.

Table 5 summarises the psychometric findings before and after operation, and the differences after operation in the two outcome groups. The performance of the control group is given for comparison. Both outcome groups show a stable pattern in the preoperative and postoperative test performance. They show a retained verbal ability, a slight but significant memory reduction, and above all, a marked deterioration of spatial memory and spatioperceptual ability (memory for design and block design tests). The positive change in the improved group was comparatively small and most marked in spatioperceptual ability $(P<0.001)$ but could also be found for immediate memory $(\mathrm{P}<0.01)$.

\section{Discussion}

The selection of cases of hydrocephalic dementia for operation was based on neurological evidence of hydrocephalus including pneumoencephalogra- 
Table 5 Preoperative and postoperative test performances in improved and unimproved patients with hydrocephalic dementia

\begin{tabular}{|c|c|c|c|c|c|c|c|}
\hline \multirow[t]{3}{*}{ Test } & \multirow{3}{*}{$\begin{array}{l}\text { Control group } \\
(n=54)\end{array}$} & \multicolumn{6}{|c|}{ Hydrocephalic dementia } \\
\hline & & \multicolumn{3}{|c|}{ Improved $(n=12)$} & \multicolumn{3}{|c|}{ Unimproved $(n=11)$} \\
\hline & & Preoperative & Postoperative & Difference & Preoperative & Postoperative & Difference \\
\hline $\begin{array}{l}\text { Vocabulary } \\
\text { Paired associates } \\
\text { Visual retention }\end{array}$ & $\begin{array}{l}27.4 / 10.9 \\
16.4 / 4.6\end{array}$ & $\begin{array}{c}20.0 / 15.4 \\
6.9 / 5.5\end{array}$ & $13.2 / 6.2$ & $6.3 / 6.3^{*}$ & $\begin{array}{l}24.9 / 16.4 \\
9.2 / 9.7\end{array}$ & $7.4 / 10.6$ & $-1.8 / 3.5$ \\
\hline $\begin{array}{l}\text { Right } \\
\text { Wrong } \\
\text { Memory for design } \\
\text { Visual retention and } \\
\text { memory for design } \\
\text { (number of patients) }\end{array}$ & $\begin{array}{l}6.2 / 1.6 \\
6.4 / 3.2 \\
2.8 / 2.6\end{array}$ & $\begin{array}{r}2.8 / 1.8 \\
11.1 / 6.1 \\
7.3 / 8.0\end{array}$ & $\begin{array}{l}4.0 / 2.1 \\
9.4 / 4.2\end{array}$ & $\begin{array}{r}2.0 / 1.9 \\
-2.9 / 7.3\end{array}$ & $\begin{array}{r}3.3 / 2.0 \\
11.7 / 4.8 \\
6.8 / 6.7\end{array}$ & $\begin{array}{r}3.4 / 1.5 \\
11.6 / 3.8\end{array}$ & $\begin{array}{r}-0.4 / 1.5 \\
0.8 / 2.7\end{array}$ \\
\hline $\begin{array}{l}\text { Can copy } \\
\text { Cannot copy } \\
\text { Block design }\end{array}$ & $\begin{array}{l}0 \\
0 \\
21.0 / 6.8\end{array}$ & $\begin{array}{l}3 \\
1 \\
7.1 / 7.7\end{array}$ & $\begin{array}{l}1 \\
0 \\
12.7 / 7.4\end{array}$ & $5.6 / 3.2 \dagger$ & $\begin{array}{l}3 \\
3 \\
4.1 / 6.5\end{array}$ & $\begin{array}{l}0 \\
6 \\
5.1 / 6.0\end{array}$ & $1.0 / 3.9$ \\
\hline
\end{tabular}

Differences tested with one-tailed $t$ test, $\mathrm{H}_{0}, \mathrm{~m} \neq 0$.

$*=\mathrm{P}<0.01, \dagger=\mathrm{P}<0.001$.

phy, RISA cisternography, and CSF measurements, and was made regardless of the psychiatric and psychometric findings. In several aspects our series of cases resembles previously published series. The aetiologies were heterogeneous. The material contained idiopathic and obstructive as well as communicating hydrocephalus. There was almost total agreement between the psychiatric and psychometric evaluations of outcome and in agreement with previous reports, about $50 \%$ of the patients improved. It should also be pointed out that the results presented are derived from a rather small number of cases.

Before the shunt operation our patients manifested a general mental deterioration in addition to a symptom constellation more specific for the group. They showed cognitive, emotional, and conative-intentional defects such as disorientation, amnesia, emotional unconcern, lack of insight, psychomotor retardation, and inertia. The strong confabulation, the peculiar gait disturbance, and the early appearance of urinary incontinence during the course of the disease seem to be a rather specific symptom pattern in the group. Psychometric tests showed general cognitive reduction including memory dysfunction but with a retained verbal ability. Most specific in this group of patients seemed to be the marked disturbance in perceptual performance and probably also in inductive reasoning. Most likely this is a manifestation of constructional apraxia (Warrington, 1969). Similar findings have been reported in one of the few psychometric studies of hydrocephalic dementia (Collignon et al., 1975).

The emotional disturbances and the amnesicconfabulatory syndrome showed important clinical similarities to frontal lobe lesions (Petrie, 1949;
Rylander, 1949; Luria, 1966, 1973), temporallimbic lesions, Scoville and Milner, 1957; Ule, 1958; Meyer, 1959; Brierley, 1961; Victor et al., 1961), and lesions of the hypothalamicdiencephalic structures (Ule, 1958; Victor et al., 1961; Victor, 1964; Lishman, 1971). Confabulation is not an uncommon feature in organic dementias (Berlyne, 1972), especially in those with frontotemporal degeneration such as Pick's disease (Brun and Gustafson, 1978). In these patients confabulation is more often accompanied by euphoria, disinhibition, increased tempo of speech, and expressive speech disturbances (Mansvelt, 1954; Escourolle, 1958; Robertson et al., 1958; Gustafson et al., 1978) while other motor functions remain undamaged. The symptom pattern of reduced speed of motor and intellectual performance, urinary incontinence, and a gait disturbance resembling Bruns' frontal lobe ataxia (Bruns, 1892) had also been connected with frontal predilection of ventricular enlargement (Adams et al., 1965; Benson et al., 1970; Mathew et al., 1975).

As seen in Table 4, our patients with hydrocephalic dementia did not have aphasic, agnostic, and apractic disturbances to the same extent as patients with Alzheimer's disease. This may reflect a less severe dysfunction of the temporo-parietooccipital association cortex in hydrocephalic dementia than in Alzheimer's disease (Critchley, 1953; Luria, 1973; Brun and Gustafson, 1976). In Alzheimer's disease the changes of muscular tension and the small step gait might sometimes cause difficulty in differential diagnosis (Sjögren et al., 1952; Pearcy, 1974; Brun and Gustafson, 1976). However, in Alzheimer's disease the urinary incontinence starts later in the course of the disease. 
As has been pointed out in our previous publications on dementia, the clinical picture in hydrocephalic dementia might be clouded by various psychiatric symptoms and reactions such as anxiety, depression, aggressiveness, and dysphoria. This is also the impression from the present study and, in fact, two cases in the best outcome group were first misdiagnosed as conversion reactions with astasia abasia.

Psychometric testing showed a general cognitive reduction with the main dysfunction within spatioperceptual performance (constructional apraxia). The findings are similar to what has been observed in patients with uraemia (Hagberg, 1974) and hepatic cirrhosis (Victor et al., 1965; Rhenström et al., 1974). This might indicate a more diffuse cerebral dysfunction in contrast to the accentuated temporo-parieto-occipital cortical degeneration in Alzheimer's disease (Brun and Gustafson, 1976). The clear difference in cognitive dysfunction between the hydrocephalic group on the one hand and early dementia, C 2 (Hagberg and Ingvar, 1976), and Korsakoff syndrome (Kleinknecht and Goldstein, 1972) on the other also supports this assumption.

Postoperative improvement was found in $50 \%$ of the hydrocephalic dementia group. The best therapeutic effect was found in patients with the specific symptom pattern. The improvement was most evident in the specific psychiatric symptoms and psychometrically in a better spatioperceptual performance. It might be justified to assume that the specific symptoms are more directly related to the hydrocephalus and that the less consistent symptoms might be related to other factors such as concomitant injuries to different brain structures (Granholm and Svendgaard, 1972), the aetiology of the hydrocephalus, or the patient's premorbid personality. Therefore positive effect of a shunt operation is more likely when there is a welldefined syndrome of hydrocephalic dementia.

There were no differences between the two outcome groups as to age or degree of cognitive reduction before operation. By contrast, the duration of the disease seems to be of great importance. The improved patients showed more specific symptoms and shorter duration than the unimproved cases. If both outcome groups represent one clinical entity, this finding might indicate a symptom change with time. The emotional reactions and the confabulation observed early in the illness might reflect the adaptive functional capacity of preserved structures (Gustafson and Hagberg, 1975). The clinical differences between the two outcome groups must also be considered against the differences in aetiology. Subarachnoid haemorrhage, obstructive hydrocephalus, and previous intracranial operation were more frequent in the improved group while idiopathic hydrocephalus and skull trauma, often in combination with alcohol addiction, were more frequent in the non-improved cases. This might, to some extent, give the differences in duration of the disease. Presence of a possible cause of hydrocephalus and a complete obstruction might lead to an earlier investigation and detection of hydrocephalic dementia.

We are indebted to the staffs of the departments of Neurology (Head: Professor R. Müller) and Neurosurgery, University Hospital, Lund, Sweden, and to Miss Eva Nilsson for efficient secretarial help.

\section{References}

Adams, R. D., Fisher, C. M., Hakim, S., Ojeman, R. G., and Sweet, W. H. (1965). Symptomatic occult hydrocephalus with "normal" cerebrospinalfluid pressure. New England Journal of Medicine, 273, 117-126.

Benson, D. F., LeMay, M., Patten, D. H., and Rubens, A. B. (1970). Diagnosis of normal-pressure hydrocephalus. New England Journal of Medicine, 283, 609-615.

Benton, A. L. (1963). The Revised Visual Retention Test. Clinical and Experimental Application. Third edition. The Psychological Corporation: New York.

Berlyne, N. (1972). Confabulations. British Journal of Psychiatry, 120, 31-39.

Brierley, J. B. (1961). Clinico-pathological correlations in amnesia. Gerontologia Clinica (Basel), 3, 97-109.

Braham, J., Front, D., Sarova-Pinhas, I., Kosary, I. Z., and Czerniak, P. (1969). Brain atrophy, hydrocephalus and dementia in adults. Israel Journal of Medical Science, 5, 1213-1218.

Brun, A., and Gustafson, L. (1976). Distribution of cerebral degeneration in Alzheimer's disease. Archiv für Psychiatrie und Nervenkrankheiten, 223, 1533.

Brun, A., and Gustafson, L. (1978). Limbic lobe involvement in presenile dementia. Archiv für Psychiatrie und Nervenkrankheiten. In press.

Bruns, L. (1892). Über Störungen des Gleichgewichtes bei Stirnhirntumoren. Deutsche Medicinische Wochenschrift, 7, 18, 138-140.

Coblentz, J. M., Mattis, S., Zingesser, L. H., Kasoff, S. S., Wisniewski, H. M., and Katzman, R. (1973). Presenile dementia. Clinical aspects and evaluation of cerebrospinal fluid dynamics. Archives of Neurology (Chicago), 29, 299-308.

Collignon, R., Rectem, D., Laterre, E. C., and Stroobandt, G. (1975). Aspect neuropsychologique de l'hydrocéphalie normopressive. Acta Neurologica Belgica, 76, 74-82. 
Critchley, M. (1953). The Parietal Lobes. Edward Arnold: London.

Cronholm, B., and Molander, L. (1954). Memory disturbances after electroconvulsive therapy. I. Conditions six hours after electroshock treatment. Acta Psychologica et Neurologica Scandinavica, 32, 280-306.

Crowell, R. M., Tew, J. M., and Mark, V. H. (1973). Aggressive dementia associated with normal pressure hydrocephalus. Report of two unusual cases. Neurology (Minneapolis), 23, 461-464.

Earnest, M. P., Fahn, S., Karp, J. H., and Rowland, L. P. (1974). Normal pressure hydrocephalus and hypertensive cerebrovascular disease. Archives of Neurology (Chicago), 31, 262-266.

Escourolle, R. (1958). La Maladie de Pick. Etude Critique d'Ensemble et Synthese Anatomo-clinique. Imprimerie R. Foucon: Paris.

Graham, F. K., and Kendall, B. S. (1960). Memoryfor-design, revised general manual. Perceptual and Motor Skills, 11, 147-188.

Granholm, L., and Svendgaard, N. (1972). Hydrocephalus following traumatic head injuries. Scandinavian Journal of Rehabilitation Medicine, 4, 31-34.

Granville-Grossman, K. (1971). Hydrocephalic dementia. In Recent Advances in Clinical Psychiatry, pp. 246-254. J. and A. Churchill: London.

Gustafson, L. (1975). Psychiatric symptoms in dementia with onset in the presenile period. Acta Psychiatrica Scandinavica, Suppl. 257, 8-35.

Gustafson, L., Brun, A., and Ingvar, D. H. (1977). Presenile dementia; clinical symptoms, pathoanatomical findings and cerebral blood flow. In Cerebral Vascular Disease, pp. 5-9. Edited by J. St. Meyer, H. Lechner, and M. Reivich. Excerpta Medica: Amsterdam.

Gustafson, L., and Hagberg, B. (1975). Emotional behaviour, personality changes and cognitive reduction in presenile dementia: related to regional cerebral blood flow. Acta Psychiatrica Scandinavica, Suppl. 257, 39-67.

Gustafson, L., Hagberg, B., and Ingvar, D. H. (1972). Psychiatric symptoms and psychological test results related to regional cerebral blood flow in dementia with early onset. In Research on the Cerebral Circulation, pp. 291-300. Edited by J. St. Meyer, M. Reivich, H. Lechner,, and O. Eichhorn. Charles C. Thomas: Springfield, Illinois.

Gustafson, L., Hagberg, B., and Ingvar, D. H. (1978). Speech disturbances in presenile dementia related to local cerebral blood flow abnormalities in the dominant hemisphere. Brain and Language, 5, 103118.

Gustafson, L., and Risberg, J. (1974). Regional cerebral blood flow related to psychiatric symptoms in dementia with onset in the presenile period. Acta Psychiatrica Scandinavica, 50, 516-538.

Hagberg, B. (1974). A prospective study of patients in chronic hemodialysis. III. Predictive value of intelligence, cognitive deficit and ego defence structures in rehabilitation. Journal of Psychosomatic Research, 18, 151-160.

Hagberg, B., and Ingvar, D. H. (1976). Cognitive reduction in presenile dementia related to regional abnormalities of the cerebral blood flow. British Journal of Psychiatry, 128, 209-222.

Husén, T. (1956). CVB-skalan. Individuell testskala för vuxna. Håkan Olssons Tryckeri: Lund.

Katzman, R. (1976). Cerebrospinal fluid physiology and normal pressure hydrocephalus. In Neurobiology of Aging, pp. 139-153. Edited by R. D. Terry and S. Gershon. Raven Press: New York.

Kleinknecht, R. A., and Goldstein, S. G. (1972). Neuropsychological deficits associated with alcoholism. Quarterly Journal of Studies on Alcohol, 33, 999-1019.

Lishman, W. A. (1971). Amnesic syndromes and their neuropathology. In Recent Developments in Psychogeriatrics. A Symposium, pp. 25-38. Edited by D. W. K. Kay, and A. Walk. British Journal of Psychiatry (special publication no. 6). Headley Brothers Ltd.: Ashford, Kent.

Luria, A. R. (1966). Higher Cortical Functions in Man. Tavistock Publications: London.

Luria, A. R. (1973). The Working Brain. An introduction to neuropsychology. Allen Lane, The Penguin Press: London.

McHugh, P. R., and Goodell, H. (1966). Hydrocephalic dementia: differential diagnosis, psychometric tests and response to treatment. Neurology (Minneapolis), 16, 299.

McNemar, Q. (1959). Psychological Statistics. John Wiley and Sons: New York.

Mansvelt van, J. (1954). Pick's disease. A syndrome of lobar, cerebral atrophy; its clinical-anatomical and histopathological types. Thesis. Enschede, Utrecht.

Mathew, N. T., Meyer, J. S., Hartman, A., and Ott, E. O. (1975). Abnormal cerebrospinal fluid-blood flow dynamics. Archives of Neurology (Chicago), 32, 657-664.

Messert, B., and Wannamaker, B. B. (1974). Reappraisal of the adult occult hydrocephalus syndrome. Neurology (Minneapolis), 24, 224-231.

Meyer, V. (1959). Cognitive changes following temporal lobectomy for the relief of temporal lobe epilepsy. Archives of Neurology and Psychiatry (Chicago), 81, 299-309.

Patzold, U., Pfingst, E., and Trostdorf, E. (1974). Der "Normal pressure hydrocephalus". Fortschritte der Neurologie, Psychiatrie und ihre Grenzgebiete, 42, 281-290.

Pearcy, J. (1974). The extrapyramidal disorder of Alzheimer's disease. European Neurology, 12, 94 103.

Petrie, A. (1949). Personality changes after prefrontal leucotomy. British Journal of Medical Psychology, 22, 200-207.

Rehnström, S., Hansson, J. A., Johnson, G., Simert, G., and Vang, J. (1974). Levercirrhos och encephalopati-erfarenheter av psykometrisk utred- 
ning av ett kirurgiskt cirrhosmaterial. Svensk Kirurgi, 31, 83-84.

Robertson, E. E., le Roux, A. V. S., and Brown, J. H. (1958). The clinical differentiation of Pick's disease. Journal of Mental Science, 104, 1000 1024.

Rylander, G. (1949). Observations on mental changes after total lobotomy and after inferior lobotomy. Acta Psychiatrica et Neurologica, Suppl. 60, 82-89.

Salmon, J. H. (1969). Senile and presenile dementia: ventriculoatrial shunt for symptomatic treatment. Geriatrics, 24, 67-72.

Salmon, J. H., Gonen, Y., and Brown, L. (1971). Ventriculoatrial shunt for hydrocephalus exvacuo: psychological and clinical evaluation. Diseases of the Nervous System, 32, 299-307.

Scoville, W. B., and Milner, B. (1957). Loss of recent memory after bilateral hippocampal lesions. Journal of Neurology, Neurosurgery, and Psychiatry, 20, 11-21.

Sjögren, T., Sjögren, H., and Lindgren, A. G. H. (1952). Morbus Alzheimer and Morbus Pick. A Genetic, Clinical and Patho-anatomical Study. Munksgaard: Copenhagen.

Smith, G., and Nyman, G. E. (1959). Psychopathological behaviour in a serial experiment. Acta Universitas Lundensis, 56, 1-53.
Theander, S., and Granholm, L. (1967). Sequelae after spontaneous subarachnoid haemorrhage, with special reference to hydrocephalus and Korsakoff's syndrome. Acta Neurologica Scandinavica, 43, 479 488.

Ule, G. (1958). Patologisch-anatomische Befunde bei Korsakow Psychosen und ihre Bedeutung für die Lokalisationslehre in der Psychiatrie. Ärtzliche Wochenschrift, 13, 6-13.

Victor, M. (1964). Observations on the amnesic syndrome in man and its anatomical basis. In Brain Functions, volume 2, pp. 31-40. Edited by M. A. B. Brazier. University of California Press: Los Angeles.

Victor, M., Adams, R. D., and Cole, M. (1965). The acquired (non-Wilsonian) type of chronic hepatocerebral degeneration. Medicine (Baltimore), 44, 345-396.

Victor, M., Angevine, J. B., Mancall, E. L., and Fisher, C. M. (1961). Memory loss with lesions of hippocampal formations. Archives of Neurology (Chicago), 5, 244-263.

Warrington, E. (1969). Constructional apraxia. In Handbook of Clinical Neurology, volume 4, pp. 67-83. Edited by P. J. Vinken and G. W. Bruyn. North-Holland: Amsterdam.

Wechsler, D. (1958). The Measurements and Appraisal of Adult Intelligence. Fourth edition. Williams and Wilkins: Baltimore. 